\title{
Ascl1 Is Required for the Development of Specific Neuronal Subtypes in the Enteric Nervous System
}

\author{
(Datima Memic, ${ }^{1}$ Viktoria Knoflach, ${ }^{1}$ @Rebecca Sadler, ${ }^{1}$ Gunilla Tegerstedt, ${ }^{2}$ Erik Sundström, ${ }^{3,4}$ @Francois Guillemot, ${ }^{5}$ \\ Vassilis Pachnis, ${ }^{5}$ and ${ }^{-O U l r i k a ~ M a r k l u n d ~}{ }^{1}$ \\ ${ }^{1}$ Division of Molecular Neurobiology, Department of Medical Biochemistry and Biophysics, Karolinska Institutet, S-17177 Stockholm, Sweden, \\ 2Department of Clinical Science, Intervention and Technology, Karolinska University Hospital, Huddinge, Karolinska Institutet, S-17177 Stockholm, \\ Sweden, ${ }^{3}$ Division of Neurodegeneration, Department of Neurobiology, Care Sciences and Society, Novum, Karolinska Institutet, S-14186 Stockholm, \\ Sweden, ${ }^{4}$ Stockholms Sjukhem Foundation, R\& D Unit, S-10226 Stockholm, Sweden, and ${ }^{5}$ Francis Crick Institute, Mill Hill Laboratory, The Ridgeway, \\ Mill Hill, London NW7 1AA, United Kingdom
}

The enteric nervous system (ENS) is organized into neural circuits within the gastrointestinal wall where it controls the peristaltic movements, secretion, and blood flow. Although proper gut function relies on the complex neuronal composition of the ENS, little is known about the transcriptional networks that regulate the diversification into different classes of enteric neurons and glia during development. Here we redefine the role of Ascl1 (Mash1), one of the few regulatory transcription factors described during ENS development. We show that enteric glia and all enteric neuronal subtypes appear to be derived from Ascl1-expressing progenitor cells. In the gut of $A s c l 1^{-1-}$ mutant mice, neurogenesis is delayed and reduced, and posterior gliogenesis impaired. The ratio of neurons expressing Calbindin, TH, and VIP is selectively decreased while, for instance, 5- $\mathrm{HT}^{+}$neurons, which previously were believed to be Ascl1dependent, are formed in normal numbers. Essentially the same differentiation defects are observed in Ascl $^{\text {KINgn } 2}$ transgenic mutants, where the proneural activity of Ngn2 replaces Ascl1, demonstrating that Ascl1 is required for the acquisition of specific enteric neuronal subtype features independent of its role in neurogenesis. In this study, we provide novel insights into the expression and function of Ascl1 in the differentiation process of specific neuronal subtypes during ENS development.

Key words: differentiation; enteric nervous system; gliogenesis; mutant mice; neurogenesis; transcription factor

\section{Significance Statement}

The molecular mechanisms underlying the generation of different neuronal subtypes during development of the enteric nervous system are poorly understood despite its pivotal function in gut motility and involvement in gastrointestinal pathology. This report identifies novel roles for the transcription factor Ascl1 in enteric gliogenesis and neurogenesis. Moreover, independent of its proneurogenic activity, Ascll is required for the normal expression of specific enteric neuronal subtype characteristics. Distinct enteric neuronal subtypes are formed in a temporally defined order, and we observe that the early-born 5 - $\mathrm{HT}^{+}$neurons are generated in $\mathrm{Ascl1}^{-/-}$mutants, despite the delayed neurogenesis. Enteric nervous system progenitor cells may therefore possess strong intrinsic control over their specification at the initial waves of neurogenesis.

\section{Introduction}

The enteric nervous system (ENS) is the largest, most phenotypically complex part of the PNS, and regulates the peristaltic move-

Received Jan. 19, 2016; revised Feb. 18, 2016; accepted Feb. 25, 2016.

Author contributions: F.M., V.K., R.S., and U.M. designed research; F.M., V.K., R.S., G.T., E.S., and U.M. performed research; G.T., E.S., F.G., and V.P. contributed unpublished reagents/analytic tools; F.M., V.K., R.S., V.P., and U.M. analyzed data; F.M., V.K., R.S., V.P., and U.M. wrote the paper.

This work was supported by the Knut and Alice Wallenberg Foundation KAW2008.0123, Swedish Research Council 521-2012-1676, EMBO, Swedish Society for Medical Research, Swedish Medical Society, Ruth and Richard Julin Foundation, Magnus Bergvall Foundation, and Åke Wiberg Foundation. We thank Reena Lasrado, Tiffany Heanue, Daniel Gyllborg, Eva Hedlund, and Moritz Lübke for constructive comments on the manuscript.

The authors declare no competing financial interests. ments, blood flow, and secretion within the gut (Furness, 2006; Sasselli et al., 2012; Obermayr et al., 2013a). The ENS is mainly derived from neural crest stem cells (NCSCs), which upon entering the foregut colonize the full extent of the bowel wall at early developmental stages. While undertaking this extensive migration, the enteric neural stem cells (ENSCs) proliferate immensely and differentiate into a multitude of distinct neuronal subtypes

Correspondence should be addressed to Dr. Ulrika Marklund, Karolinska Institutet, Department of Medical Biochemistry and Biophysics, Unit of Molecular Neurobiology, Scheeles väg 1, S-17177 Stockholm, Sweden. E-mail: Ulrika.Marklund@ki.se.

DOI:10.1523/JNEUROSCI.0202-16.2016

Copyright $\odot 2016$ the authors $\quad 0270-6474 / 16 / 364339-12 \$ 15.00 / 0$ 
and enteric glia in a nonsynchronized manner (Sasselli et al., 2012). Developmental failure to form neurons in the distal part of the gut results in the most well-characterized ENS disorder, Hirschsprung disease. In other ENS-linked diseases (e.g., achalasia), specific subtypes of neurons are selectively affected (Furness, 2006, 2012). Despite the critical role of distinct neuronal subtypes for gut function and a significant progress in understanding the molecular basis to ENSC migration and proliferation, today there is little knowledge of the regulatory mechanisms and networks of transcription factors controlling the diversification of ENSCs into different classes of enteric neurons during development.

Considerable recent advances have been made in identifying gene regulatory networks that control the development of clinically relevant neuronal subtypes in other parts of the PNS and in the CNS (Kiyasova and Gaspar, 2011; Lallemend and Ernfors, 2012; Hegarty et al., 2013). One transcription factor that has been implicated in cell fate specification is Ascl1 (Mash1), which belongs to the proneural family of neural bHLH genes [also including Neurogenin (Ngn) 1-3 and Math1]. Through loss-of-function (LOF) analyses, Ascl1 was initially identified as a key regulator of neurogenesis in both PNS and CNS, but gain-of-function (GOF) experiments suggested additional roles in regulating subtypespecific aspects of neuronal differentiation (Guillemot et al., 1993; Hirsch et al., 1998; Lo et al., 1998; Fode et al., 2000). To investigate these functions separately, Parras et al. (2002) generated transgenic mice $\left(A s c l 1^{\text {KINgn2 }}\right)$, where the coding region of Ascl1 was replaced by $\mathrm{Ngn} 2$. In Ascl1 ${ }^{\mathrm{KINgn2}}$ mutants, neurogenesis is rescued in many regions of the CNS, revealing the critical requirement for Ascl1 in subtype differentiation, for instance, of hindbrain 5-HT neurons and spinal V2a interneurons (Parras et al., 2002; Pattyn et al., 2004).

Ascl1 is expressed in ENSCs, and previous studies have indicated a role in both enteric neurogenesis (Lo et al., 1991; Guillemot et al., 1993; Lo and Anderson, 1995; Sang et al., 1999) and the selective formation of an enteric neuronal subtype $\left(5-\mathrm{HT}^{+}\right)$(Blaugrund et al., 1996). However, it is unclear whether Ascll expression is confined to specific ENSC populations and what possible roles it has in the generation of the various enteric neurons and glia. Considering the importance of Ascl1 in the formation of accurate types and numbers of neurons during CNS development, we sought to make a comprehensive study of the functions of Ascl1 in the developing ENS. Our data indicate that progenitors of all enteric neuronal subtypes and enteric glia express Ascll at early stages of development. In the gut of $\mathrm{Ascl}^{-/-}$mutant mice, gliogenesis is locally impaired, whereas neurogenesis is notably delayed and reduced. We identified selective reductions in the percentage of neurons expressing Calbindin (stomach, small intestine), VIP (stomach), and TH (stomach). These abnormal ratios of selective neuronal subgroups were not due to the delayed onset of neurogenesis as a similar phenotype was observed in $\mathrm{Ascl}^{\mathrm{KINgn2} 2}$ mutants, where Ngn2 rescues enteric neurogenesis. Together, these data demonstrate novel roles for Ascl1 in the acquisition of specific neuronal subtype characteristics during ENS development, redefining the prevailing model of Ascll function in the diversification of enteric neurons.

\section{Materials and Methods}

Mouse and human embryos. The generation of Ascl1 ${ }^{\text {CreERT2 }}$ (The Jackson

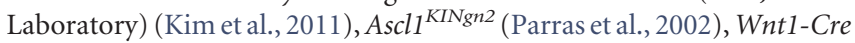
(Danielian et al., 1998), and R26ReYFP (Srinivas et al., 2001) mouse lines has previously been described. Ascl1 ${ }^{\text {CreERT2/CreERT2 mutant embryos are }}$ denoted $\mathrm{Ascl1}^{-1-}$ throughout this paper. Remains of human embryos and fetuses (5.5 and 8 weeks after conception) were collected after elective routine abortions with written consent given by the pregnant woman. Collection of tissue for research was approved by the Regional Human Ethics Committee, Stockholm.

Tissue preparation. E10.5-13.75 mouse embryos were collected and fixed in $4 \%$ PFA in PBS, pH 7.4, at $4^{\circ} \mathrm{C}$ for 1.5 h. E15.5 and E18.5 guts were dissected out from the embryos and fixed for $2 \mathrm{~h}$. Human gut tissue was fixed for $2 \mathrm{~h}$. Samples were subsequently washed in PBS at $4^{\circ} \mathrm{C}$ for $1 \mathrm{~h}$ and cryoprotected by incubating at $4^{\circ} \mathrm{C}$ overnight in $30 \%$ sucrose in PBS. The tissue was embedded in OCT (Histolab) and stored at $-80^{\circ} \mathrm{C}$. Samples were cryosectioned at $14 \mu \mathrm{m}$ and stored at $-20^{\circ} \mathrm{C}$ after drying at room temperature for $1 \mathrm{~h}$.

In situ hybridization. In situ hybridization on cryosections was performed as previously described (Briscoe et al., 2000). The isolation of Ret cDNA was described by Pachnis et al. (1993).

Immunohistochemistry. Fluorescent immunohistochemical stainings were performed as described previously (Briscoe et al., 2000) using the following primary antibodies: mouse HuC/D (1:300; Molecular Probes), Ascl1 (1:300; BD Biosciences Pharmingen), Math1 (1:20; DSHB); goat Chat (1:500; Millipore), Sox10 (1:200; Santa Cruz Biotechnology), NeuroD1 (1:100; Santa Cruz Biotechnology), Ngn1 (1:500; Santa Cruz Biotechnology), GFP (488-conjugated, 1:1000; Abcam); rabbit Ki67 (1:500; Thermo Scientific), NPY (1:3000; DiaSorin), VIP (1:2500; Abcam), cleaved caspase-3 (1:1000; Cell Signaling Technology), CGRP (1:1000; Immunostar), NOS1 (1:500; Santa Cruz Biotechnology), substance P (1:1000; Millipore Bioscience Research Reagents), Calbindin (1:1000; Millipore Bioscience Research Reagents), TH (1:500; Pelfreeze), 5-HT (1:2000; Sigma), S100 (1:1000; DAKO), Blbp (1:300; Millipore), Ngn2 (1:500; Millipore), Sox2 (1:4000; Seven Hill Bioreagents), and guinea pig Sox10 (1:1000, kind gift from M. Wegner). Primary antibodies were detected with secondary antibody conjugated with AlexaFluor-488, -555, and -647 (Invitrogen) or CY5 (Jackson ImmunoResearch Laboratories).

5-Ethynyl-2'-deoxyuridine (EdU) and tamoxifen experiments. Time plug-mated $A s c l 1{ }^{\text {CreERT2 }}$ and $A s c l 1^{\text {KINgn2 }}$ mice received a single intraperitoneal injection of EdU $(0.1 \mathrm{mg} / \mathrm{g}$ animal; Invitrogen $)$ at E12.5. Mice were killed $90 \mathrm{~min}$ after injection. Embryos were prepared for immunohistochemistry as described above. Tissue sections were first immunostained for $\mathrm{HuC} / \mathrm{D}$ and Sox 10 and then reacted for EdU using the Click iT EdU AlexaFluor-488 Imaging kit (Invitrogen). After 20 min, slides were washed in PBS and mounted. Time plug-mated Ascl1 ${ }^{\text {CreERT2 }} \times$ R26ReYFP mice received intraperitoneal injection of tamoxifen dissolved in peanut oil $(0.1 \mathrm{mg} / \mathrm{g}$ animal, Sigma) at E10.5 and/or E13.5. E18.5 embryos were collected and prepared as described.

Statistical analysis and imaging. All cells were counted on a minimum of 5 sections (up to 15 sections) per investigated region of the gut in mutant and littermate wt embryos. Paired Student's $t$ test comparisons were performed for all statistical examinations. Bars indicate mean \pm SD; $n=3-6$. The images were taken using a Zeiss LSM700 confocal microscope and processed in Adobe Photoshop CS6 or ImageJ (National Institutes of Health). Counting of fluorescent cells was performed using the "Cell Counter" plugin in ImageJ or directly under a Zeiss fluorescent microscope.

\section{Results}

Ascl1 is transiently expressed in progenitors and precursors of all perinatal enteric neuronal subtypes

To investigate the expression pattern of Ascll in the developing mouse gut, we performed fluorescent immunohistochemistry on cryosections from embryonic day 9.5 (E9.5) to E18.5. Onset of Ascl1 expression correlated with the NCSC entry into the foregut and was present in the majority of these cells as assessed by coexpression with YFP in Wnt1-Cre $\times$ R26ReYFP E9.5 embryos (Fig. 1A) (Lo et al., 1991). Throughout development, Ascl1 was primarily confined to the Sox $10^{+}$population, which corresponds to the ENSCs, both in the stomach and small intestine ( $\sim 55 \%$; Fig. $1 E-G, K)$. In addition, a subset of cells expressing the neuronal marker $\mathrm{HuC} / \mathrm{D}$, colabeled with Ascll at early stages (Fig. $1 B, L$ ). Most Ascl1 ${ }^{+} \mathrm{HuC} / \mathrm{D}^{+}$cells coexpressed Sox10 and the cell cycle marker Ki67 (Fig. 1C,D), indicating that they were immature neurons. Between E15.5 and E18.5, Ascl1 expression was only 

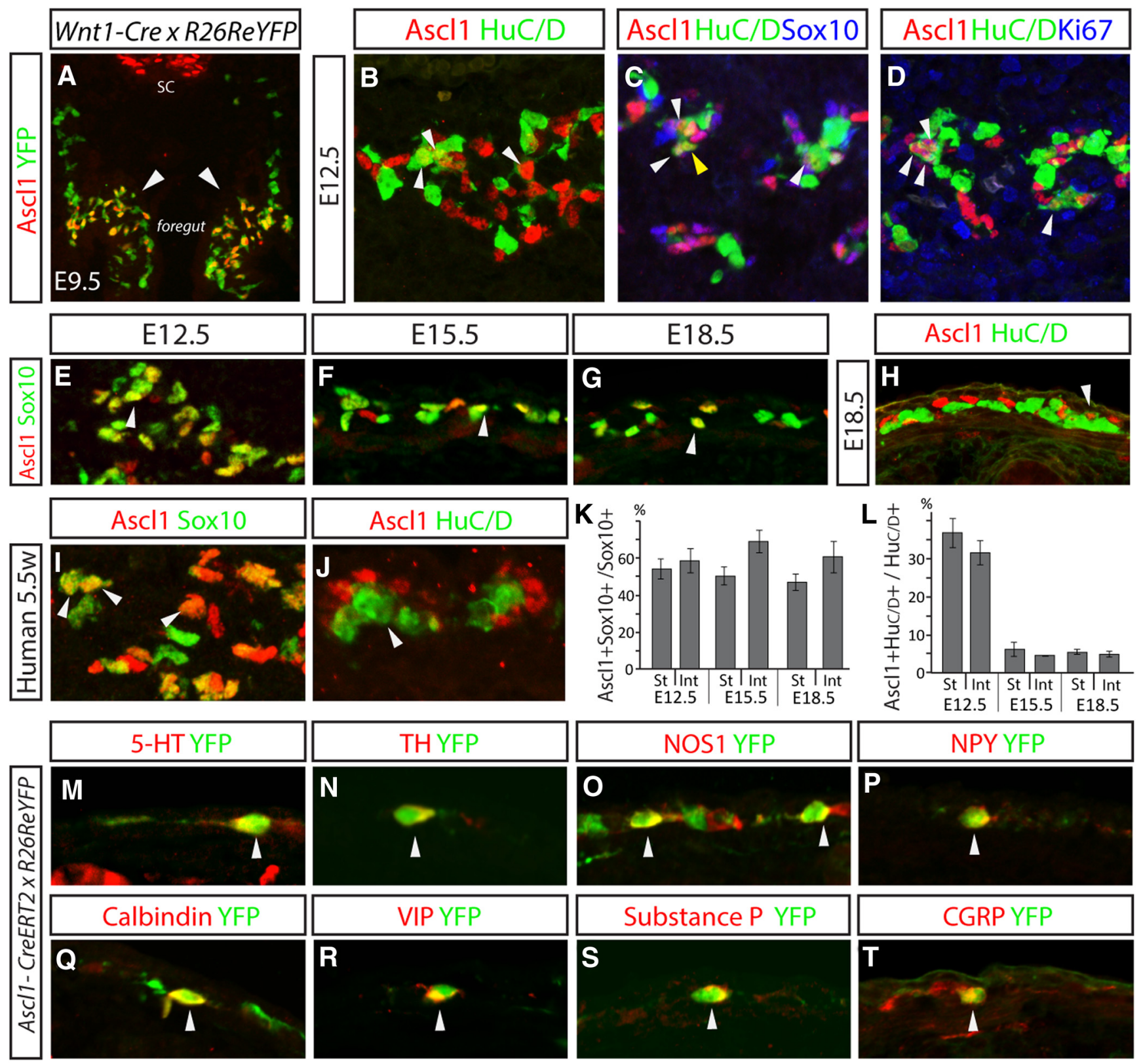

Figure 1. All enteric neuronal subtypes at perinatal stages are derived from $\mathrm{Ascl} 1{ }^{+}$progenitors. $A$, Ascl1 is expressed (arrowheads), in NCSCs migrating into the foregut as shown by coexpression with YFP in Wnt1-Cre $\times$ R26ReYFPreportermiceatE9.5. Many HuC/D ${ }^{+}$cells coexpress Ascl1 (arrowheads) atE12.5 (B), whereas only few HuC/D ${ }^{+} \mathrm{AsCl1}^{+}$atE18.5 (H).C, MostHuC/D ${ }^{+}$Ascl1 ${ }^{+}$cells areSox10 ${ }^{+}$(white arrowheads), but some are Sox $10^{-}$(yellow arrowhead). $\boldsymbol{D}, \mathrm{HuC}_{\mathrm{D}}{ }^{+}$Sox $10^{+}$cells express Ki67 (arrowheads). The expression of Asc11 is mainly confined to Sox $10^{+}$cells at E12.5 (E), E15.5 (F), and E18.5 (G) (arrowheads). Ascl1 is expressed in a majority of Sox $10^{+}$cells $(\boldsymbol{I})$ and a few HuC/D cells $(\boldsymbol{J})$ in 5.5 week human embryos (arrowheads). Graphs depicting the ratio of Sox $10^{+}(\boldsymbol{K})$ or HuC/D ${ }^{+}(\boldsymbol{L})$ cells expressing Ascl1 at different stages and gut regions. $M-T$, Ascl1 is expressed in progenitors of all neuronal subtypes at E18.5 shown by YFP immunoreactivity together with 5-HT (M), TH (N), NOS1 (O) , NPY (P), Calbindin $(\mathbf{Q})$, VIP $(\boldsymbol{R})$, substance $P(\mathbf{S})$, and $\left(\mathrm{GRP}(\boldsymbol{T})\right.$ (arrowheads) in Asc17 $7^{\text {(reeRR2/+ }} \times$ R26ReYFP reporter mice induced with tamoxifen at E10.5 and E13.5. All pictures show immunohistochemical stainings of St. (B-E, $I, J, N, P)$ or Int. $(\boldsymbol{F}-\boldsymbol{H}, \mathbf{M}, \mathbf{O}, \mathbf{Q}-\boldsymbol{T})$. sc, Spinal cord; St., stomach; Int., small intestine. Bars indicate means \pm SD. $n=4$ or 5 .

detected in very few $\mathrm{HuC} / \mathrm{D}^{+}$cells $(\sim 5 \%$; Fig. $1 \mathrm{H}, \mathrm{L})$. Together, this analysis indicates that Ascl1 is mainly expressed in Sox $10^{+}$ ENSCs but also maintained for a short period in neuronal precursors and turned off during neuronal maturation. This expression pattern of Ascl1 appeared to be conserved among higher vertebrates as Ascl1 was detected in the human developing ENS in a majority of Sox $10^{+}$progenitors and in a few $\mathrm{HuC} / \mathrm{D}^{+}$cells, at 5.5 and 8 weeks (Fig. 1I,J; data not shown).

The fact that not all Sox $10^{+}$cells expressed Ascl1 at early stages could indicate that Ascll expression is confined to subsets of ENSCs dedicated to generating specific neuronal subtypes. Alternatively, Ascll is expressed in all ENSCs but in an oscillatory pattern, which appears to be the main mode of expression in neuronal progenitors in the CNS (Imayoshi et al., 2013). To investigate these possibilities, we used inducible transgenic mice in which Ascll expression could be traced with an eYFP reporter (Ascl1 ${ }^{\text {CreERT2/+ }} \times$ R26ReYFP) (Kim et al., 2011). To target as many Ascl ${ }^{+}$cells as possible without risking toxic effects of tamoxifen, induction was performed at E10.5 and E13.5. Embryos were analyzed at E18.5 for coexpression between YFP and the neuronal subtype markers expressed at this stage. Serotonin (5-HT), tyrosine hydroxylase (TH), nitric oxide synthase 1 (NOS1) neuropeptide Y (NPY), Calbindin (Calb1), vasoactive intestinal peptide (VIP), substance P (SubP), calcitonin gene- 

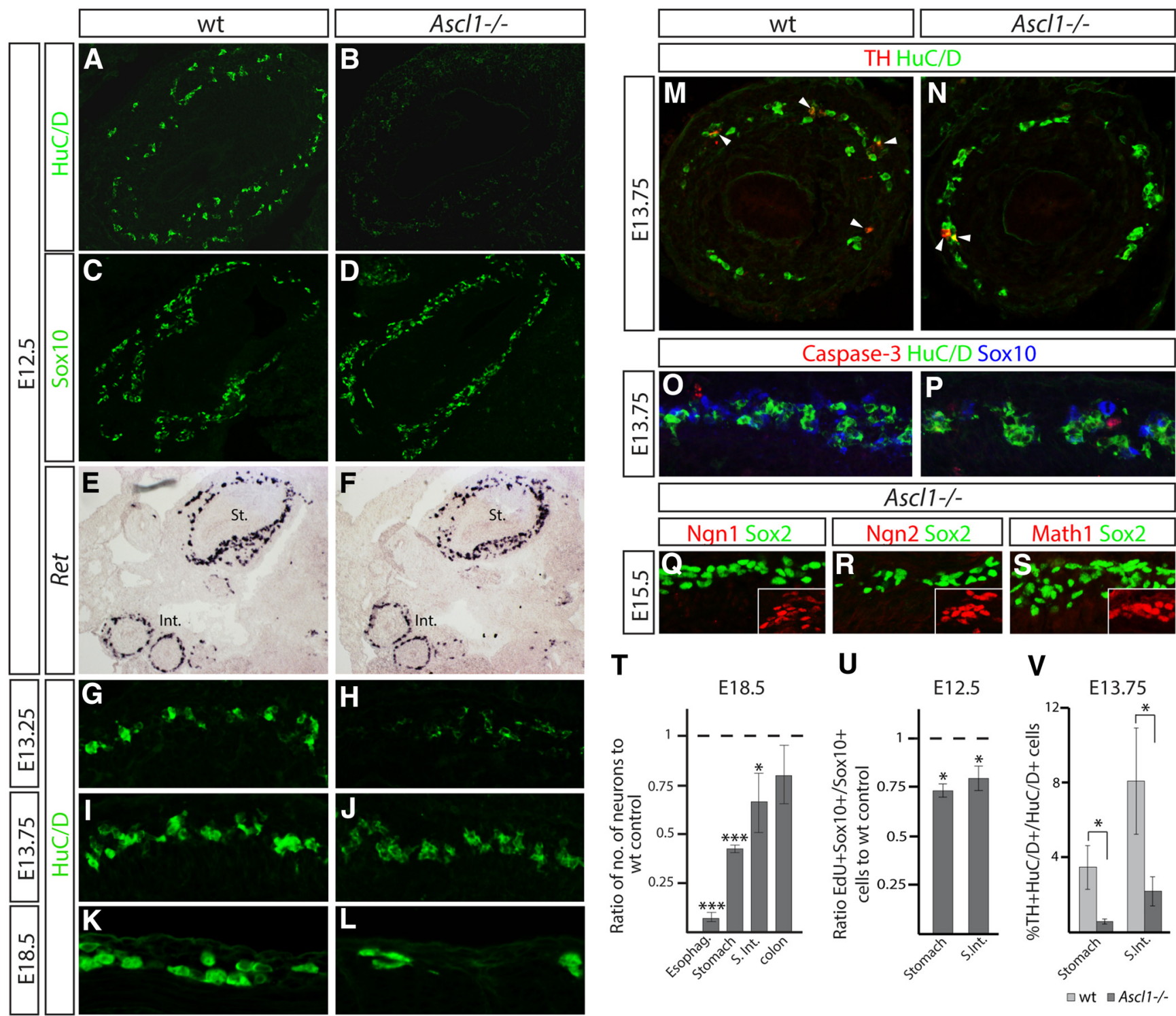

T

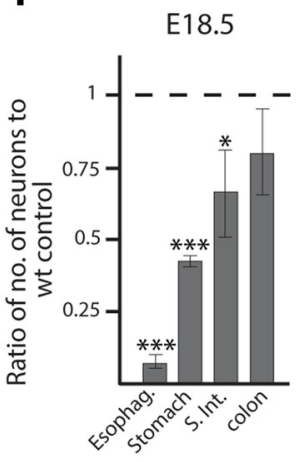

$\mathbf{U}$

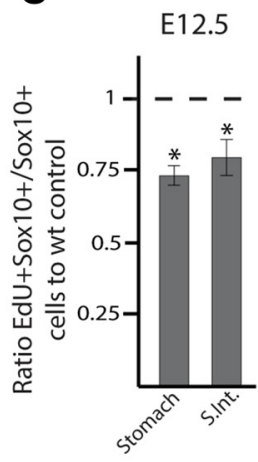

V

E13.75

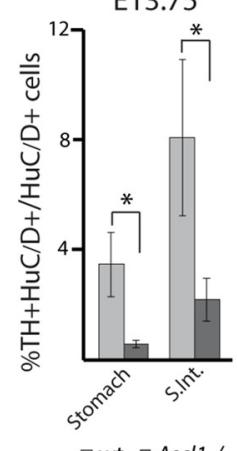

Figure 2. The enteric neurogenesis is delayed and reduced in $A s c / 1^{-1-}$ embryos. $A, B, A t E 12.5$, many cells express HuC/D in wt controls, but no or only weak HuC/D ${ }^{+}$cells can be detected in Ascl1 $1^{-/-}$embryos. The number and distribution of Sox10 $(\boldsymbol{C}, \boldsymbol{D})$ and Ret $(\boldsymbol{E}, \boldsymbol{F})$ expressing cells at E12.5 are similar in wt and $A s c 11^{-/-}$embryos. G-J, Between E13.25 and E13.75, expression of HuC/D changes from being faint in a few cells to strong and defined in many cells in the stomach. $K, L, A t E 18.5$, the number of HuC/D-expressing cells is decreased in the stomach of $A s c / 1^{-/}{ }^{-}$mutant embryos. $\boldsymbol{M}, \boldsymbol{N}$, The number of neurons expressing TH (arrowheads) is diminished in Ascl1 ${ }^{-1-}$ mutants compared with control embryos at E13.75. $\mathbf{0}, \boldsymbol{P}$, There is no increased active caspase-3 expression in $A s \mathrm{Cl} 1^{-/-}$embryos compared with wt embryos. Q-S, Ngn1, Ngn2, and Math1 were detected at E12.5 in the dorsal spinal cord (insets) but not in the ENS of Ascl1 ${ }^{-/-}$mutant embryos at E15.5. Sox2 ${ }^{+}$cells are ENSCs (Heanue and Pachnis, 2011). $T$, Graph showing the ratio of numbers of neurons in Ascl1 ${ }^{-/}$mutant embryos compared with wt controls at different parts of the gut at E18.5. $\boldsymbol{U}$, Graph showing that the ratio of Sox $10^{+}$cells that incorporated EdU after a 90 min pulse injection is slightly reduced in $A s c 11^{-1-}$ mutants compared with wt controls at E12.5. V, Graph showing the percentage of $\mathrm{HuC} / \mathrm{D}^{+}$neurons that express $\mathrm{TH}$ in $A s \mathrm{AC}^{-1-}$ mutants compared with in wt control embryos at E13.75. The control was set to 1 in $T, U$. All pictures show immunohistochemical staining, except $\boldsymbol{E}, \boldsymbol{F}$, where in situ hybridization was applied. St.: $\boldsymbol{A}-\mathbf{D}, \mathbf{G}-\mathbf{L}, \mathbf{O}-\mathbf{S} ;$ Int: $\boldsymbol{M}, \boldsymbol{N}$. S. Int., Small intestine; $n=3-5$. Bars indicate means $\pm S D .{ }^{*} p<0.05$, ${ }^{* * *} p<0.001$.

related peptide (CGRP), and choline acetyltransferase (ChAT) were all detected in $\mathrm{YFP}^{+}$cells at all regions investigated (stomach and/or small intestine and/or large intestine) (Fig. 1M-T; data not shown). These data demonstrate that Ascl1 ${ }^{+}$progenitors are capable of generating all phenotypically different neurons present at perinatal stages, suggesting that Ascl1 is expressed in the progenitors of all neuronal subtypes.

Loss of Ascl1 does not affect ENSC migration but results in delayed and reduced neurogenesis

To evaluate the role of Ascl1 in ENS development, we next analyzed the gut of Ascl1 mutant mice in which a CreER ${ }^{\mathrm{T} 2}$ cassette had replaced the entire coding region of Ascll
(Ascl1 ${ }^{\text {CreERT2/CreERT2 }}$ ) (Kim et al., 2011). For simplicity, we hereafter denote homozygote embryos from this mouse line $\mathrm{Ascl}^{-/-}$. Previous studies of an Ascl1 LOF mouse line (Guillemot et al., 1993) have shown that deletion of this locus delays the enteric neurogenesis resulting in essential loss of neurons in the esophagus and reduced numbers of neurons in the stomach and intestine (Guillemot et al., 1993; Blaugrund et al., 1996; Sang et al., 1999). We compared wild-type (wt) and $A s c l 1^{-/-}$embryos throughout the development and found that at stages E10.5E12.5, when HuC/D expression is initiated in the ENS of wt embryos, $\mathrm{HuC} / \mathrm{D}$ immunoreactivity was virtually undetectable in the gut of $A s c l 1^{-/-}$embryos (Fig. 2A,B; data not shown). Between E13.25 and 13.75, many strongly expressing $\mathrm{HuC} / \mathrm{D}^{+}$neu- 
ronal precursors appeared in the gut of $A s c l 1^{-/-}$mutants, thus with a 3 d delay (Fig. $2 G-J$ ). A fraction of immature neurons are transiently catecholaminergic $\left(\mathrm{TH}^{+}\right.$) at $\sim$ E10-E14 (Baetge and Gershon, 1989), and these cells have been reported lost in Ascl1 LOF mutants (Blaugrund et al., 1996). In our analysis, TH was detected at E13.75 concurrently with the first $\mathrm{HuC} / \mathrm{D}^{+}$neurons albeit in reduced proportions $(\sim-80 \%)$ compared with control embryos (Fig. $2 M, N, V$ ). Because Ascl1 LOF mutant mice die shortly after birth (Guillemot et al., 1993), the latest possible time-point for analysis was at E18.5-E19. At this stage, many $\mathrm{HuC} / \mathrm{D}^{+}$enteric neurons were observed in the guts of $\mathrm{AsCl}^{-/-}$ mutants, but with a clear reduction compared with wt guts. The decrease was most pronounced in the anterior portions of the gastrointestinal tract, and there was a gradual normalization of neuronal numbers toward the posterior end (esophagus $(-93 \pm$ $2.2 \%)$; stomach $(-58 \pm 2.0 \%)$; small intestine $(-34 \pm 16 \%)$; and colon $(-20 \pm 15 \%$, not significant) (Fig. $2 K, L, T)$. That neurons eventually are generated in $A s c l 1^{-/-}$mutants could indicate an upregulation of partially compensating alternative proneural genes. However, we did not detect expression of Ngn1, Ngn2, or Math1 in the gut of either wt or $A s c l 1^{-/-}$mutant embryos, although immunoreactivity was readily observed in the spinal cord (Fig. 2Q-S; data not shown). In summary, these data show a delayed neurogenesis and diminished, but not abolished, transient expression of $\mathrm{TH}$ in the gut of $\mathrm{Ascl1}^{-/-}$mutants.

The deficient neurogenesis in $\mathrm{AsCl}^{-1-}$ mutant embryos prompted us to investigate whether other basic cellular processes, such as migration, proliferation, and survival, were impaired in the absence of Ascl1. At E12.5, we observed similar numbers of cells expressing the early ENSC marker Ret throughout the gastrointestinal tract in $\mathrm{Ascl1}^{-/-}$and wt control embryos, indicating that mutant ENSCs migrated normally (Fig. 2 E,F). The number of Sox $10^{+}$cells was also not altered in the mutant compared with control guts at E12.5 (Fig. 2C,D). The ratio of Sox $10^{+}$cells in the S-phase of the cell cycle, incorporating the nucleoside analog EdU after a $2 \mathrm{~h}$ pulse were slightly decreased in the mutant versus control embryos (Fig. 2U). This could indicate that progenitors at this stage are only slowly dividing or temporarily stalled in the cell cycle in the absence of Ascl1. We also did not observe any increased cell death in the ENS of $\mathrm{AsCl}^{-/-}$mutants compared with wt as assessed by cleaved caspase- 3 expression at E13.75 (Fig. $2 O, P)$. Together, this analysis suggests that Ascll function is not crucial for ENSCs migration and survival but required for the timely initiation of neuronal differentiation.

\section{The expression of specific enteric neuronal subtype markers is reduced in the gut of $\mathrm{Ascl1}^{-/-}$mutants}

We next addressed whether the generation of specific enteric neuronal subtypes was affected in the $A s c l 1^{-/-}$mutants. Because Ascl1 mutants die shortly after birth, we focused our analysis on representative segments of the stomach (St.) and small intestine (S.Int.) at E18.5-E19. At this stage, the following subtype markers are expressed in wt embryos: (St.) 5-HT, VIP, NOS1, Calbindin, TH, NPY; (S.Int.) 5-HT, VIP, NOS1, Calbindin, and CGRP. SubP and ChAT are also detectable, but the staining is punctate and therefore difficult to quantify. Robust expression of Calretinin and GABA has not yet commenced at E18.5. To unequivocally compare the expression of subtype marker genes in $\mathrm{Ascl}^{-/-} \mathrm{em}-$ bryos to littermate wt controls (in which the number of $\mathrm{HuC} / \mathrm{D}^{+}$ neurons were higher), we compared the percentage of neurons expressing a given subtype marker. In the stomach, the percentage of neurons expressing Calbindin, VIP, or TH was substantially reduced ( $-60 \%$ to $-70 \%$ compared with control) (Fig.
$3 A, B, E, F, Q, R, W, X)$. The Calbindin-expressing proportion of neurons was equally affected in the S.Int as in the stomach $(-60 \%$ ) (Fig. $3 C, D, W, X)$. VIP, however, was not significantly reduced in the S.Int (Fig. $3 G, H, W, X$ ). The number of neurons expressing TH was too low to quantify in the S.Int; but although scattered $\mathrm{TH}^{+}$cells were observed in the wt control, hardly any were found in the mutant (data not shown). Surprisingly, 5- $\mathrm{HT}^{+}$ neurons, which are thought to require Ascll for their differentiation (Blaugrund et al., 1996), were generated in normal to slightly increased (however nonsignificant) ratios in $\mathrm{Ascl}^{-/-}$ embryos compared with wt controls (Fig. $3 M-P, W, X$ ). The two markers, which had the most similar neuronal ratios in mutant and control, were CGRP (S.Int.) and NPY (St.) (Fig. 3S-V). NOS1 expression was slightly increased in the S.Int (30\%) but not significantly different from control in the St. (Fig. $3 I-L, W, X$ ). Together, in the gut of $A s c l 1^{-/-}$mutants, the ratios of neurons expressing Calbindin, VIP, and TH in the stomach, and Calbindin in the small intestine were drastically reduced. In contrast, the percentage of neurons expressing CGRP, NPY, 5-HT, NOS1 (St.), and VIP (St.) was not significantly different to control, whereas NOS1 neurons (S.Int.) were generated in an increased proportion compared with wt control embryos (Fig. $3 W, X$ ).

\section{The neurogenic deficiency in the absence of Ascll can be rescued by $\mathrm{Ngn} 2$ in $\mathrm{Ascl}^{\mathrm{KINgn2}}$ mutants}

The decreased expression of selective enteric subtype markers in the gut of $\mathrm{Ascl1}^{-/-}$embryos indicates that Ascll is not merely involved in enteric neurogenesis but also plays a role in neuronal subtype specification. However, as neurogenesis was perturbed in the absence of Ascl1, the reduction of neurons expressing specific subtype markers could be due to a delay in marker expression. To distinguish between the neurogenic function of Ascl1 and its potential role in neuronal subtype specification, we analyzed a transgenic knock-in mouse $\left(A s c l 1^{K I N g n 2}\right)$, in which the coding region of $A s c l 1$ was replaced with the proneural gene $\mathrm{Ngn2}$, a gene that is capable of rescuing the neurogenic deficits of Ascl1 $^{-1-}$ mice in the CNS (Parras et al., 2002; Pattyn et al., 2004). At E12.5, when the ENS of $A s c l 1^{-/-}$mutant had not yet started to express $\mathrm{HuC} / \mathrm{D}$ (Fig. $2 B$ ), we observed normal or slightly increased numbers of $\mathrm{HuC} / \mathrm{D}^{+}$cells in Ascl1 ${ }^{\text {KINgn2 }}$ mutants (Fig. $4 A, B)$, demonstrating that Ngn2 can rescue the neurogenesis defect in the ENS of $A s c l 1^{-/-}$mutants. The neurogenesis appeared to be induced at the normal stage as only very few $\mathrm{HuC} / \mathrm{D}^{+}$cells were present at E10.5 in the gut of both Ascl1 ${ }^{\text {KINgn2 }}$ and wt embryos (data not shown). Analysis of the ENS at E18.5 showed no difference in the final number of $\mathrm{HuC} / \mathrm{D}^{+}$neurons generated in $A s c l 1^{\text {KINgn2 }}$ embryos compared with wt controls $(104.3 \pm 9.2 \%$ in the small intestine; Fig. $4 C, D, J)$. However, similar to in $\mathrm{Ascl1}^{-/-}$embryos, there was a reduced ratio of neurons transiently expressing $\mathrm{TH}$ at E12.5 (-80\%; Fig. 4E, F,L). Proliferation appeared to be unaffected in $\mathrm{AsCl}^{\mathrm{KINgn2}}$ mutants as indicated by similar numbers of Sox $10^{+}$cells compared with control and the same ratio of EdU ${ }^{+} \operatorname{Sox} 10^{+} /$Sox $10^{+}$cells after a $2 \mathrm{~h}$ pulse in the gut of mutant and wt embryos at E12.5 (Fig. $4 \mathrm{~K}$; data not shown). To verify that Ngn2 did not confer properties normally associated with tissues regulated by Ngns, we examined expression of NeuroD1, which is a transcriptional target of Ngns (Ma et al., 1996; Sommer et al., 1996; Seo et al., 2007). At E12.5, when Ngn2-expressing tissues, such as the DRGs and intermediate spinal cord, showed high expression of NeuroD1 (Fig. 4G), we did not detect expression in the ENS of either $\mathrm{Ascl1}^{\mathrm{KINgn2}}$ or wt control embryos (Fig. 4H,I). Together, our analysis shows that 


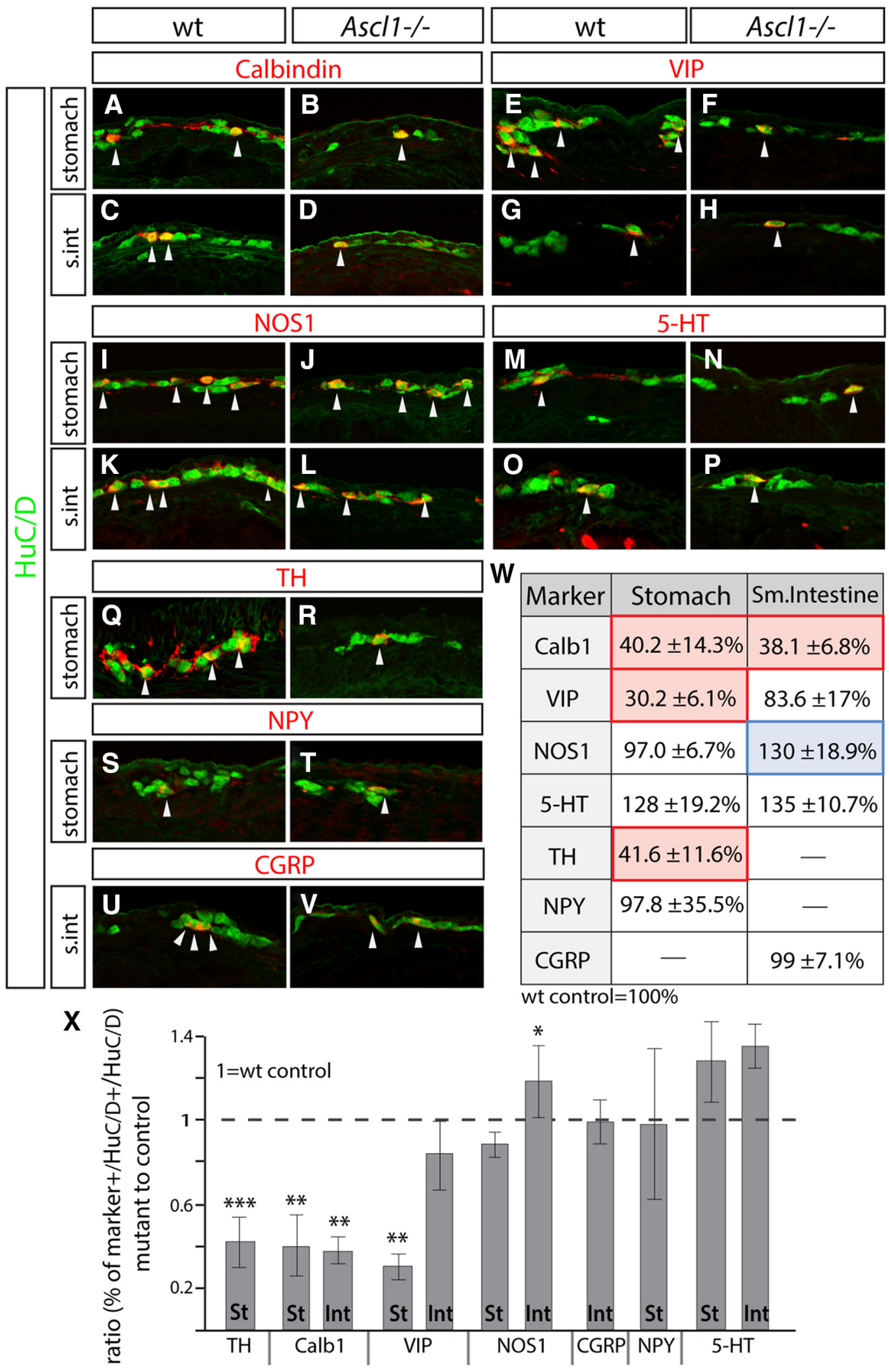

Figure 3. The ratio of neurons expressing specific subtype markers is reduced in the gut of $A s\left(11^{-/-}\right.$mutant mice. $A-V$, Representative pictures of the stomach (St.) and small intestine (S.Int.) at E18.5 in wt and $A s c 11^{-1-}$ embryos showing drastically reduced ratios of neurons (marker ${ }^{+} / \mathrm{HuC} / \mathrm{D}^{+}$; arrowhead) expressing Calbindin $(\boldsymbol{A}-\boldsymbol{D}), \mathrm{VIP}(\boldsymbol{E}, \boldsymbol{F})$, and TH $(\boldsymbol{Q}, \boldsymbol{R})$, a slight increased ratio of NOS1 $(\boldsymbol{K}, \boldsymbol{L})$ and no effect on $5-\mathrm{HT}(\boldsymbol{M}-\boldsymbol{P}), \operatorname{VIP}(\boldsymbol{G}, \boldsymbol{H}), \operatorname{NOS1}(\boldsymbol{I}, \boldsymbol{J}), \operatorname{NPY}(\boldsymbol{S}, \boldsymbol{T})$, and $\mathrm{GGRP}(\boldsymbol{U}, \boldsymbol{V})$ neuronal ratios. $\boldsymbol{W}$, The percentage of HuC/D ${ }^{+}$neurons expressing either of the markers (mean \pm SD) was calculated in the gut of $\mathrm{AsCl} 1^{-1-}$ mutants and wt controls at E18.5-E19. The table shows the percentages in $\mathrm{AsCl}^{-1-}$ embryos compared with wt controls (set to 100\%). Red boxes represent a relative decrease. Blue box represents an increase compared with control. $X$, Graph showing the ratio of the percentage of neurons in the Ascl1 ${ }^{-/-}$embryos expressing the various submarkers $(\boldsymbol{A}-\boldsymbol{V})$ compared with the percentage in the wt controls (set to 1). All pictures show immunohistochemical stainings. $n=4-6$. Bars indicate means \pm SD. ${ }^{*} p<0.05,{ }^{* *} p<0.01$, ${ }^{* * *} p<0.001$ 


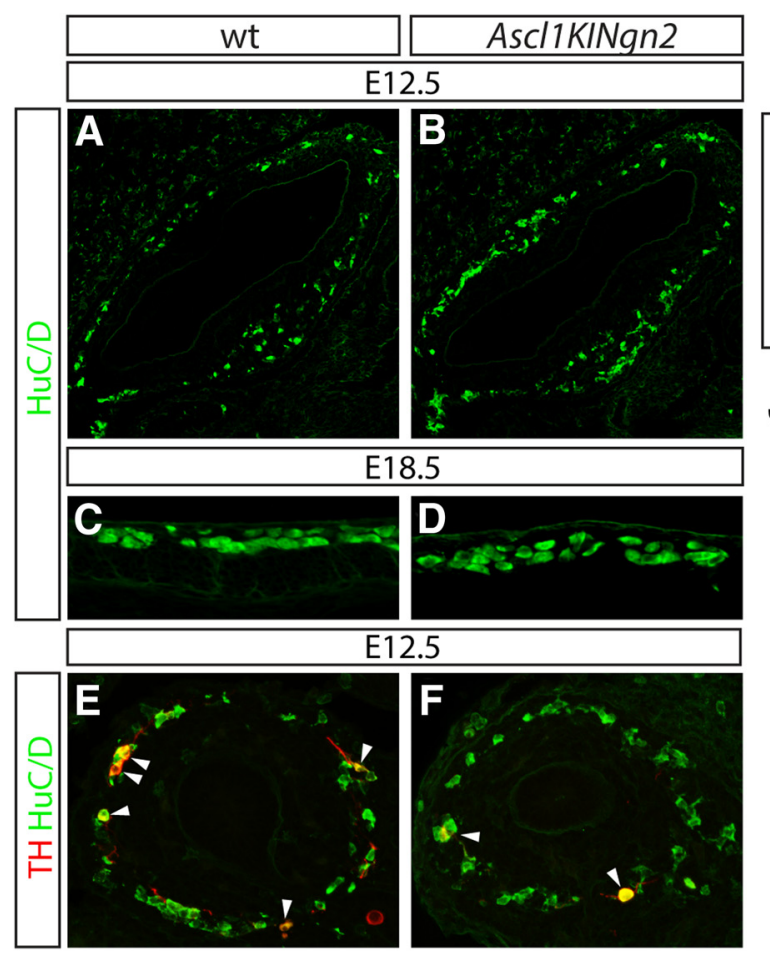

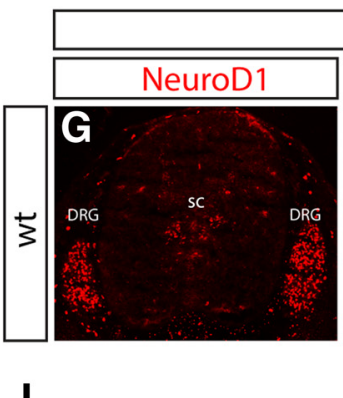

E18.5

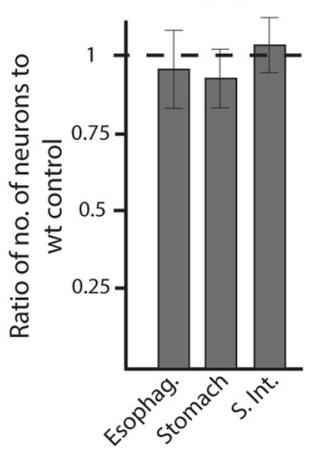

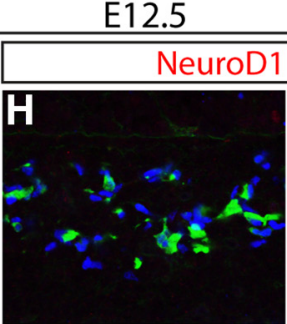

K

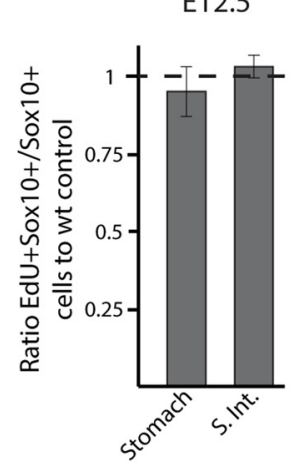

$\mathbf{L}$

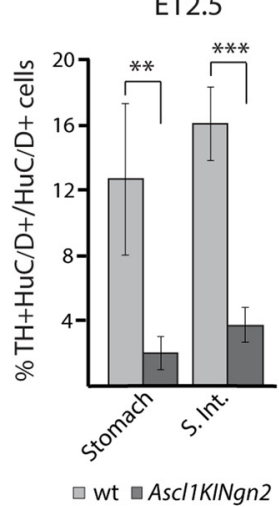

Figure 4. The neurogenic impairment in the absence of Ascl1 is rescued in Ascl $17^{K I N g n 2}$ embryos. A-D, At E12.5 and E18.5, Ascl1 $7^{K I g n n 2}$ mutant embryos have similar numbers of HuC/D ${ }^{+}$cells compared with wt controls. $\boldsymbol{E}, \boldsymbol{F}$, The number of neurons expressing TH (arrowheads) is reduced in Ascl $7^{K I N g n 2}$ mutants compared with wt controls at E12.5. G-I, NeuroD1 expression is present at E12.5 in the SC and DRG, but not in the ENS of wt and Ascl $7^{\text {KINgn2 } 2}$ mutants. J, Graph showing the ratio of the number of neurons in Ascl $7^{K I N g n 2}$ compared with control embryos in various parts of the gut. $K$, Graph showing that the ratio of Sox $10^{+}$cells that incorporated EdU after a 90 min pulse injection is similar in wt and Ascl $7^{K I N g n 2}$ mutant embryos at E12.5. L, Graph showing the percentage of HuC/D+ ${ }^{+}$cells expressing TH in Ascl/ $7^{K I N g n 2}$ and control embryos. Control was set to 1 in $J, K$. All pictures show immunohistochemical stainings of $S t$. $(\boldsymbol{A}-\boldsymbol{D}, \boldsymbol{H}, \boldsymbol{I})$ or Int. $(\boldsymbol{E}, \boldsymbol{F})$. DRG, Dorsal root ganglia; sc, spinal cord; S.Int., small intestine. $n=4$ or 5. Bars indicate means \pm SD. ${ }^{* *} p<0.01,{ }^{* * *} p<0.001$.

the proneural activity of Ngn2 can compensate for Ascl1 in Ascl1 ${ }^{\text {KINgn2 }}$ embryos and induce normal neurogenesis in the ENS without respecifying the ENSCs.

\section{Ascl1 is required for the acquisition of selective neuronal} subtype characteristics during ENS development

As enteric neurogenesis is restored in $A s c l 1^{\text {KINgn2 }}$ mutants, we next determined subtype marker expression in the gut of these animals. For this, we performed a similar analysis to that performed in $\mathrm{AsCl1}^{-/-}$mutants, counting the percentage of neurons expressing the various subtype markers in the stomach and small intestine at E18.5-E19. We observed that the ratio of neurons expressing Calbindin (St., S.Int), VIP (St.), and TH (St.) was drastically reduced in $A s c l 1^{\text {KINgn2 }}$ mutants ( $-60 \%$ to $-80 \%$; Fig. $5 A-D-F, Q, R, W, X)$, whereas VIP (S.Int.), 5-HT (St., S.Int), NPY (St.), and CGRP (S.Int.) were unaffected compared with control embryos (Fig. 5G, H,M-P,S-X). NOS1 expression was normal in the St. and marginally decreased in the S.Int compared with wt embryos (Fig. $5 I-L, W, X$ ). Thus, despite rescued neurogenesis in the gut of $A s c l 1^{\text {KINgn2 }}$ mutants, the proportions of neurons expressing specific neuronal subtype markers were similar to that observed in $\mathrm{Ascl1}^{-/-}$mutants, indicating that Ascl1 function is required for the normal differentiation of specific neuronal subtypes (Fig. $5 W, X$ ).

Enteric glial marker expression is reduced in the posterior gut of $A s c l 1^{-1-}$ and $A s c l 1^{\text {KINgn2 }}$ mutants

Considering that Sox10 is expressed in enteric glia in addition to ENSCs and that the majority of the Sox $10^{+}$cells throughout development were $\mathrm{Ascl1}^{+}$(Fig. $1 E-G, K$ ), we next addressed whether Ascl1 is expressed in progenitors and/or precursors of the glial lineage. To test whether glial-producing ENSCs express Ascl1, we lineage-traced Ascl1 ${ }^{+}$cells using Ascl1 ${ }^{\text {CreERT2/+ }} \times$ R26ReYFP animals, induced at E10.5 with tamoxifen. Analysis at E18.5 showed coexpression between YFP and the glial markers S100 and Blbp (Fig. 6A,B). Furthermore, we found coexpression between Ascl1 and S100 or Blbp at both E15.5 and E18.5 in wt mice (Fig. 6C,D; data not shown). Together, these experiments show that Ascl1 is expressed both in glial (or bipotential) progenitors and glial precursors during ENS development.

Next, to assess the function Ascl1 might have in gliogenesis, we analyzed the expression of glial markers at the latest possible stage (E18.5) in the gut of both $A s c l 1^{-/-}$and $A s c l 1^{\text {KINgn2 }}$ mutant mice. The number of Sox $10^{+}$cells appeared slightly reduced in both mutants but was only significantly lower in the distal part of the Ascl1 ${ }^{\text {KINgn2 }}$ $(\sim-20 \%)$ mutants compared with wt controls (Fig. $6 H, I)$. To specifically address the glial proportion of the Sox $10^{+}$cells, we calculated the ratio of Sox 10 cells expressing the more mature marker S100 and found a reduction $(\sim-50 \%)$ in the ileum and colon but a normal ratio in the jejunum in $A s \mathrm{Cl}^{-/-}$mutants compared with control embryos (Fig. 6E,F,H). In Ascl1 ${ }^{\text {KINgn2 }}$ mutants, the $\mathrm{S} 100^{+}$Sox $10^{+} /$Sox $10^{+}$ratio was close to normal in the jejunum and ileum, but a $40 \%$ reduction was observed in the colon compared with control embryos (Fig. 6E, G,I). S100 immunostaining in the anterior regions (esophagus and stomach) was indistinct in cell bodies at E18.5 and therefore hard to quantify, although no obvious differences between wt and the Ascl1 mutants were observed. At E15.5, S100 staining was well defined also anteriorly and the $\mathrm{S} 100^{+}$Sox $10^{+} /$Sox $10^{+}$ratio was not different in the stomach of Ascl1 $^{-/-}$and $A s c l 1^{\text {KINgn2 }}$ mutants compared with controls $(-5 \pm$ 


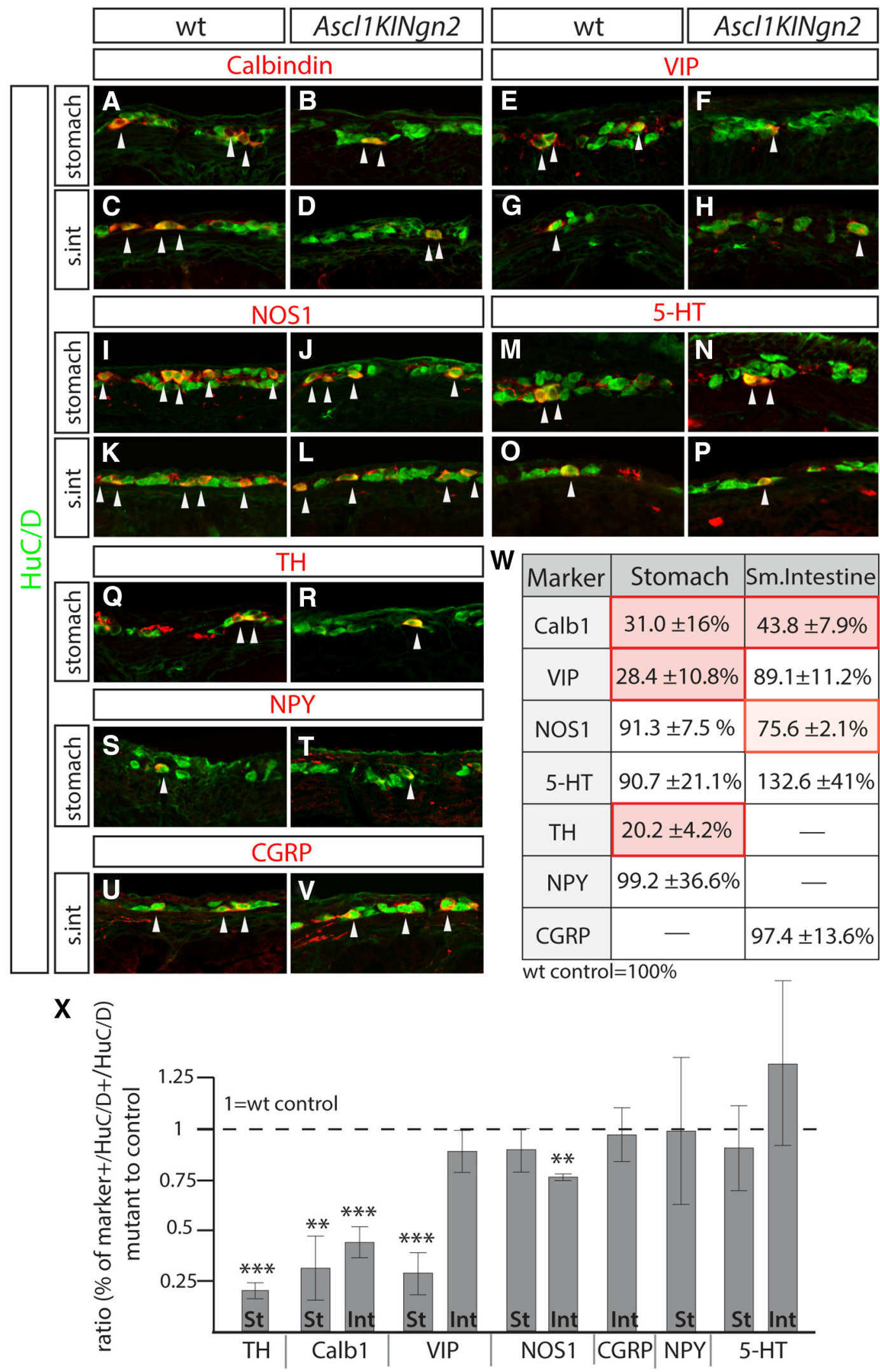

Figure 5. The ratio of neurons expressing specific subtype markers is reduced in the gut of Ascl $7^{K I N g n 2}$ mutant mice. $\boldsymbol{A}-\boldsymbol{V}$, Representative pictures of the stomach (St.) and small intestine (s. Int) at E18.5 in wt and $A s c / 7^{K I N g n 2}$ embryos showing drastically reduced ratios (marker ${ }^{+} / \mathrm{HuC} / \mathrm{D}^{+}$; arrowhead) of neurons expressing Calbindin $(\boldsymbol{A}-\boldsymbol{D}), \mathrm{VIP}(\boldsymbol{E}, \boldsymbol{F})$, and TH $(\boldsymbol{Q}, \boldsymbol{R})$, a slight reduction of the ratio of NOS1 $(\boldsymbol{K}, \boldsymbol{L})$ and no effect on $5-\mathrm{HT}(\boldsymbol{M}-\boldsymbol{P}), \operatorname{VIP}(\boldsymbol{G}, \boldsymbol{H}), \operatorname{NOS1}(\boldsymbol{I}, \boldsymbol{J}), \operatorname{NPY}(\boldsymbol{S}, \boldsymbol{T})$, and $\operatorname{GRP}(\boldsymbol{U}, \boldsymbol{V})$ neuronal ratios. $\boldsymbol{W}$, The percentage of HuC/D ${ }^{+}$neurons expressing either of the markers (mean \pm SD) was calculated in the gut of Asc $1{ }^{K I N g n 2}$ mutants and wt controls at E18.5-E19. The table shows the percentages in Ascl ${ }^{K / N g n 2}$ mutants compared with wt controls (set to $100 \%$ ). Red boxes represent a relative decrease compared with control. $\boldsymbol{X}$, Graph showing the ratio of the percentage of neurons in the $A s c\left(1^{K / N g n 2}\right.$ mutants expressing the various submarkers (A-V) compared with the percentage in the wt controls (set to 1). All pictures show immunohistochemical stainings. $n=4-6$. Bars indicate means \pm SD. ${ }^{* *} p<0.01,{ }^{* * *} p<0.001$. 

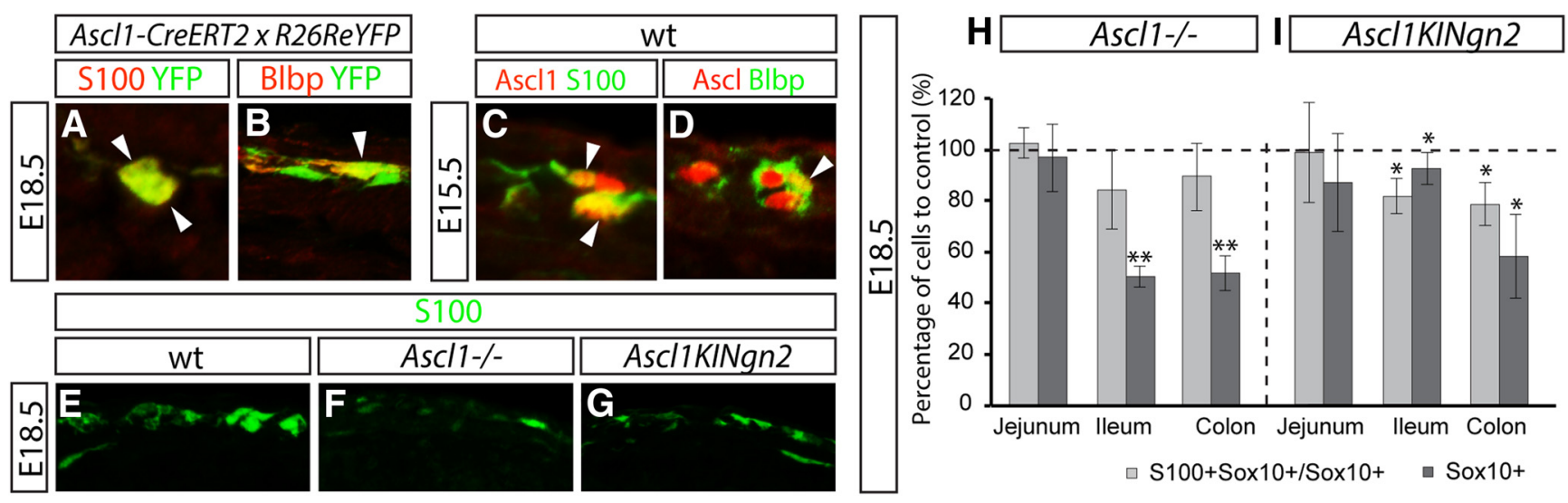

Figure 6. Glial precursors express Ascl1, and glial numbers are reduced in the posterior ENS of $A s c 11^{-/-}$and $A s C 17^{K I N g n 2}$ mutants. $A, B$, Ascl1 is expressed in progenitors of enteric glia as shown by YFP expression (arrowheads) together with S100 and Blbp in Ascl1 $7^{\text {CreERT2/+ }} \times$ R26ReYFP reporter mice induced with tamoxifen at E10.5 and harvested at E18.5. C, D, At E15.5, subsets of S100 ${ }^{+}$ and Blbp ${ }^{+}$cells coexpress Ascl1 (arrowheads). $\boldsymbol{E}-\mathbf{G}$, The ratio of Sox $10^{+}$cells expressing $\mathrm{S} 100$ is reduced in the posterior gut of $A s C l 1^{-1-}$ and Ascl1 ${ }^{\mathrm{KINgn2} 2}$ embryos compared with wt controls. $\boldsymbol{H}$, I, Graphs showing the percentage of Sox10 cells or $\mathrm{S} 100^{+}$Sox $10^{+} / \mathrm{Sox} 10^{+}$in $A s c 11^{-I-}(\boldsymbol{H})$ and Ascl $7^{\text {KINgn2 }}(\boldsymbol{I})$ embryos compared with wt controls (set to 100\%) at E18.5. All pictures show immunohistochemical stainings. $n=4$ or 5 . Bars indicate means \pm SD. ${ }^{*} p<0.05,{ }^{* *} p<0.01$.
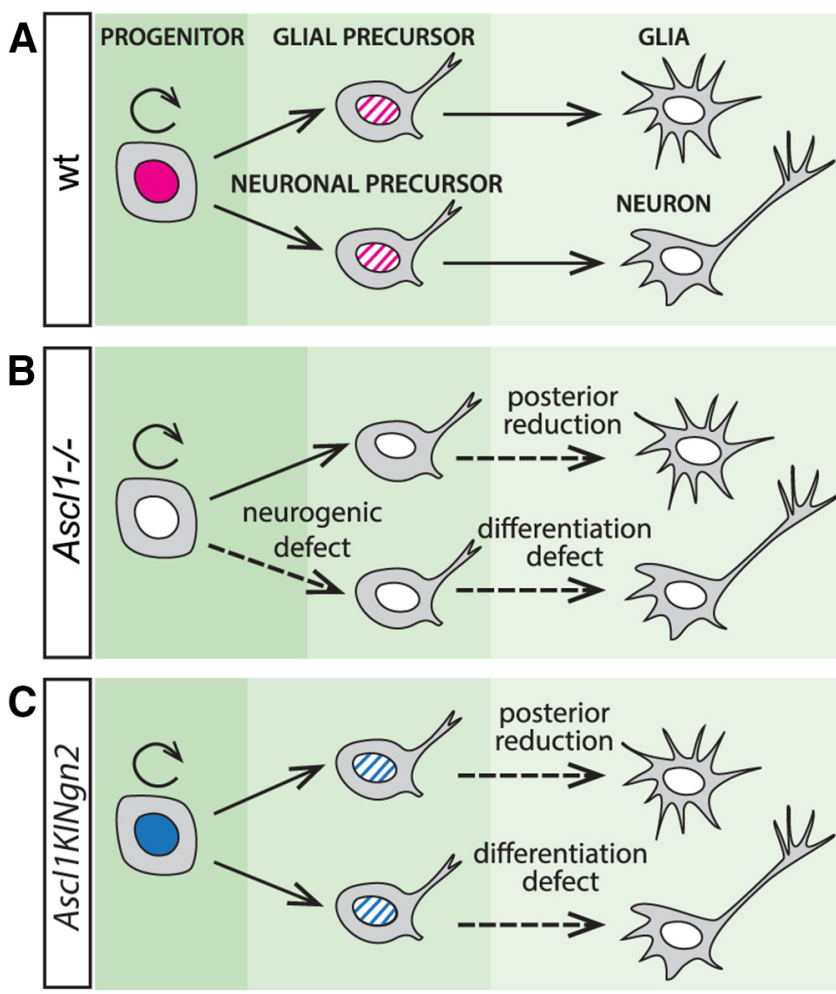

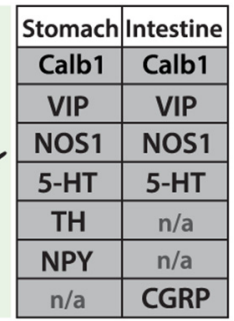

Figure 7. Schematic drawing summarizing the role of Ascl1 in enteric neurogenesis, neuronal subtype differentiation, and gliogenesis. $A$, Ascl1 (magenta) is expressed in the majority of progenitor cells at a given time, is transiently maintained in glial and neuronal precursors, and turned off in mature glia and neurons. $\boldsymbol{B}, \operatorname{In} A s\left(1^{-/-}\right.$mutant mice, glial marker expression is reduced posteriorly and the neurogenesis is delayed and reduced. The percentages of neurons expressing Calbindin, VIP, and TH are reduced, while the ratio of NOS1 ${ }^{+}$neurons is slightly increased. C, In Ascl $17^{K I N g n 2}$ mutant mice where the coding region of Ascl1 is replaced with the proneural gene $\mathrm{Ngn} 2$ (blue), the neurogenesis is rescued but a mild defect in glial marker expression remains. The ratios of neurons expressing Calbindin, VIP, and TH are similar as in $\mathrm{AsC1} 1^{-1-}$ mutants, whereas the ratio of NOS1 ${ }^{+}$neurons is slightly decreased. In summary, we show that Ascl1 is required for the appropriate timing of neurogenesis and for the acquisition of specific neuronal subtype characteristics during ENS development. n/a, Not applicable.

$14 \% ; 2 \pm 24 \%$ ), whereas statistically significant reductions were observed in the colon $(-32 \pm 17 \% ;-38 \pm 12 \%)$ similar to at E18.5. Thus, in the absence of Ascll, gliogenesis appears to be compromised in the posterior part of the bowel and cannot be fully compensated for by Ngn2 expression.

\begin{tabular}{|c|c|}
\hline Stomach & Intestine \\
\hline Calb1 & Calb1 \\
\hline VIP & VIP \\
\hline NOS1 & NOS1 \\
\hline $5-H T$ & $5-H T$ \\
\hline TH & $n / a$ \\
\hline NPY & n/a \\
\hline n/a & CGRP \\
\hline
\end{tabular}

\begin{tabular}{|c|c|}
\hline Stomach & Intestine \\
\hline Calb1 & Calb1 \\
\hline VIP & VIP \\
\hline NOS1 & NOS1 \\
\hline $5-H T$ & $5-H T$ \\
\hline TH & n/a \\
\hline NPY & n/a \\
\hline n/a & CGRP \\
\hline
\end{tabular}

\section{Discussion}

The mechanisms and transcriptional networks, which regulate the sequential generation of distinct types of enteric neurons in the developing gut, are largely unknown. This study demonstrates novel roles for Ascl1 in the acquisition of specific enteric neuronal subtype traits, amending the prevailing model of Ascll expression and function during ENS development (Fig. 7). Our data suggest that all neuronal subtypes and glia arise from $\mathrm{Ascl}^{+}$progenitors (Fig. $7 A$ ), in which Ascl1 is required for a properly timed neurogenesis and normal gliogenesis (Fig. 7A-C). By analyzing and comparing $\mathrm{Ascl1}^{-1-}$ (Fig. $7 \mathrm{~B}$ ) and Ascl1 ${ }^{\text {KINgn2 }}$ (Fig. 7C) mutant embryos, we reveal that normal expression of Calbindin, VIP, and TH (but not 5-HT) requires Ascl1, independent of its function in neurogenesis.

The role of Ascl1 in gliogenesis and neurogenesis during ENS development In the absence of Ascll, sympathetic neurons are atrophic and delayed in their formation (Guillemot et al., 1993). In contrast, partial ENS ganglia do form, although their generation is delayed, similar to what has been observed in regions of the CNS (e.g., nucleus of the solitary tract) (Guillemot et al., 1993; Blaugrund et al., 1996; Pattyn et al., 2006). This indicates the presence or upregulation of proteins with addition$\mathrm{al} /$ compensatory proneural activity in the ENS. As we did not detect Ngn1, Ngn2, or Math1 in Ascl1 $^{-/-}$embryos, plausible compensatory candidates could instead be Phox $2 \mathrm{~b}$ and Dlx proteins, which have generic proneural properties and are expressed in the developing ENS (Anderson et al., 1997; Dubreuil et al., 2002; Elworthy et al., 2005; Heanue and Pachnis, 2006). 
At perinatal stages, very few neurons are present in the esophagus, whereas the numbers increase posteriorly reaching normal amounts in the colon of $A s c l 1^{-/-}$embryos. This could reflect that normal gangliogenesis of the bowel depends on differentiation (i.e., differentiated cells are more likely to stay and form ganglia than are proliferating cells). Thus, the neurogenic delay in Ascl1 ${ }^{-/-}$mutants may have enabled ENSCs to migrate through the anterior parts leaving slightly fewer numbers of cells behind. Moreover, as normal neurogenesis occurs in an anterior to posterior gradient, the relative neurogenic delay would be shorter at posterior regions, enabling a close to normal neurogenesis in the colon. Also, the ENS of the colon is partially derived from sacral NCSCs, which potentially could be less sensitive than vagal ENSCs to loss of Ascll.

We observed decreased numbers of Sox $10^{+}$cells expressing the glial marker S100 at E18-E19 in the absence of Ascl1 at posterior regions of the gut. As Ascl1 ${ }^{\text {KINgn2 }}$ mutants display a similar phenotype (albeit milder), it is probably not only a secondary consequence of the abnormal neurogenesis. Rather, it could be that Ascll participates in the process of gliogenesis, a role that has been attributed to Ascll in the CNS. For example, studies in the spinal cord have shown that Ascl1 regulates the maturation of oligodendrocytes and generation of appropriate numbers of astrocytes (Battiste et al., 2007; Sugimori et al., 2008; Vue et al., 2014).

\section{The function of Ascl1 in enteric neuronal subtype differentiation}

Ascl1 regulates neuronal subtype differentiation of distinct neurons in the CNS (Parras et al., 2002; Pattyn et al., 2004) and direct transcriptional targets of Ascll have been identified comparing LOF and GOF genome-wide expression profiling with ChIP-chip promoter analysis (Castro et al., 2011). It was discovered that Ascll controls the acquisition of specific neuronal subtype features both by direct transcriptional regulation (e.g., TH) and secondary downstream transcriptional cascades. Using GeneFriends software (www.GeneFriends.org) (van Dam et al., 2015) for coexpressed genes, we found that VIP and TH have a high association with Ascl1 (fifth highest transcription factor, $p=$ 7.12e-04), whereas NOS1, CGRP, and NPY were not linked to Ascl1. These findings are in agreement with our data that Ascl1 regulates VIP and TH (either directly or indirectly) but not NOS1, CGRP, or NPY.

The specific reductions of Calb1 ${ }^{+}, \mathrm{VIP}^{+}$, and $\mathrm{TH}^{+}$neurons in the stomach and Calb1 ${ }^{+}$neurons in the intestine of Ascl1 LOF mutants $\left(\mathrm{Ascl}^{-/-}\right.$and $\left.\mathrm{Ascl1}{ }^{\mathrm{KINgn} 2}\right)$ indicate that the differentiation of certain subgroups of enteric neurons had been compromised. The neuronal subtypes of the stomach are poorly characterized, in contrast to the ileum (small intestine) where 16 subgroups have been defined (Sang and Young, 1996; Sang et al., 1997; Qu et al., 2008; Mongardi Fantaguzzi et al., 2009). Calbindin is expressed in CGRP ${ }^{+}$ intrinsic primary afferent neurons, but also in an uncharacterized $\mathrm{CGRP}^{-}$neuronal subpopulation (Qu et al., 2008). We believe that the lost Calb ${ }^{+}$cells are likely to correspond to the Calb ${ }^{+} \mathrm{CGRP}^{-}$ rather than intrinsic primary afferent neurons because CGRP expression was not altered in the Ascl1 LOF mutants. In further support of this, Ascl1 LOF mutants displayed a marked reduction of transient catecholaminergic $\left(\mathrm{TH}^{+}\right)$cells, which recently have been fate-mapped to generate Calb ${ }^{+}$neurons but only a small proportion of intrinsic primary afferent neurons (Obermayr et al., 2013b). The combined loss of multiple markers (TH and Calb1) at sequential stages during $\mathrm{Calb}^{+} \mathrm{CGRP}^{-}$neuron differentiation in the absence of Ascll indicates an early requirement for Ascll during the specification process of this neuronal subgroup. Thus, our data sup- port that $\mathrm{Calb}^{+} \mathrm{CGRP}^{-}$neurons are reduced or have incomplete expression profiles in the absence of Ascl1, but we are unable to determine the identity of the lost $\mathrm{TH}^{+}$and $\mathrm{VIP}^{+}$neurons. However, of interest is that gut biopsies from patients with Parkinson's disease show pathology, affecting primarily $\mathrm{TH}^{+}$and $\mathrm{VIP}^{+}$neurons. (Wakabayashi et al., 2010). Although given less attention than the hallmark motor symptoms, Parkinson's disease commonly involves significant gastrointestinal dysfunction that may be associated to the effect seen on these neuronal subtypes (Fasano et al., 2015).

The ratio of neurons expressing NOS1 in the small intestine was slightly increased in $A s c l 1^{-/-}$mutants. One possible explanation could be that the lost Calb $1^{+}$cells had been undergoing a fate switch to $\mathrm{NOS}_{1}{ }^{+}$neurons. Alternatively, $\mathrm{NOS}^{+}{ }^{+}$neurons could be generated in normal absolute numbers because they are born relatively late (peaking at E15.5) (Bergner et al., 2014). In $A s c l 1^{\text {KINgn2 }}$ mice, the percentage of $\mathrm{NOS}^{+}{ }^{+}$neurons was slightly decreased in the small intestine, making it the only marker that was differentially affected in the two mutants. In these embryos, the neurogenesis appeared to be slightly enhanced at early stages, which perhaps could explain the negative impact on the generation of late born $\mathrm{NOS}^{+}$neurons.

The Ascl1-independent generation of 5- $\mathrm{HT}^{+}$neurons in the current study contradicts a previous analysis of an Ascl1 LOF mutant in which substantial loss of 5-HT neurons was reported (Blaugrund et al., 1996). One important difference between the present and previous study is the detection methodology of 5-HT neurons. We used antibodies with high affinity and selectivity to 5-HT, providing quantifiable detection of $5-\mathrm{HT}^{+}$neurons. The previous study applied radioautography to measure retrograde uptake of ${ }^{3} \mathrm{H}-5-\mathrm{HT}$, which relies on a functional 5-HT-transporter (SERT). However, SERT has been shown to be expressed in nonserotonergic cells in other parts of the developing PNS and in the CNS (Narboux-Nême et al., 2008; Chen et al., 2015). To our knowledge, the specificity of SERT expression to 5-HT cells has not been addressed in the developing ENS, making the validity of the 5-HT reuptake assay uncertain. Nevertheless, a combined account of our two studies of Ascl1 LOF mutants could point to that 5-HT producing cells are made, but have compromised functionality.

Birth-dating studies have demonstrated that the different enteric neurons are born in a temporally defined pattern; and in this, $5-\mathrm{HT}^{+}$neurons are generated at early developmental time points, peaking at E11.5 (Pham et al., 1991; Bergner et al., 2014). In Ascl1 ${ }^{-/-}$mutants, neurogenesis is delayed $3 \mathrm{~d}$, commencing at E13.5. Despite this, we detected normal to slightly increased percentages of neurons expressing 5-HT at E18-E19. This could indicate that, at least in the first phase of the neurogenic period, ENSCs possess a strong intrinsic sequential order of differentiation occurring accurately even when delayed, seemingly unaffected by possible changes occurring in the external microenvironment.

\section{The relevance of Ascl1 in ENS disorders and regenerative medicine}

We demonstrate that Ascl1 is expressed in the developing human ENS. Considering the important role for Ascl1 in enteric development in the mouse, it is possible that allelic Ascl1 variants could predispose to human gastrointestinal deficiencies. Mutations in Ascl1 have been identified in patients with Ondine's curse, a syndrome including Hirschsprung disease (de Pontual et al., 2003), lending support for this idea.

The prospect of developing novel regenerative strategies to treat ENS disorders (e.g., Hirschsprung disease) emphasizes the requirement of understanding the differentiation cascades of dis- 
tinct enteric neuronal subtypes. In other contexts, Ascl1 is being explored in its utility of converting various cell types to neurons. For instance, Liu et al. (2015) showed that forced Ascll expression could convert midbrain astrocytes into functional neurons. Enteric glia are similar to CNS astrocytes; and following injury to the ENS, there is a spontaneous conversion of enteric glia to neurons during which Ascl1 is transiently expressed (Laranjeira et al., 2011). Therefore, one could speculate whether overexpression of Ascll in enteric glia could be used as a strategy to make new enteric neurons (perhaps specific types) in vivo in future treatments of enteric disorders.

\section{References}

Anderson SA, Qiu M, Bulfone A, Eisenstat DD, Meneses J, Pedersen R, Rubenstein JL (1997) Mutations of the homeobox genes Dlx-1 and Dlx-2 disrupt the striatal subventricular zone and differentiation of late born striatal neurons. Neuron 19:27-37. CrossRef Medline

Baetge G, Gershon MD (1989) Transient catecholaminergic (TC) cells in the vagus nerves and bowel of fetal mice: relationship to the development of enteric neurons. Dev Biol 132:189-211. CrossRef Medline

Battiste J, Helms AW, Kim EJ, Savage TK, Lagace DC, Mandyam CD, Eisch AJ, Miyoshi G, Johnson JE (2007) Ascll defines sequentially generated lineage-restricted neuronal and oligodendrocyte precursor cells in the spinal cord. Development 134:285-293. CrossRef Medline

Bergner AJ, Stamp LA, Gonsalvez DG, Allison MB, Olson DP, Myers MG Jr, Anderson CR, Young HM (2014) Birthdating of myenteric neuron subtypes in the small intestine of the mouse. J Comp Neurol 522:514-527. CrossRef Medline

Blaugrund E, Pham TD, Tennyson VM, Lo L, Sommer L, Anderson DJ, Gershon MD (1996) Distinct subpopulations of enteric neuronal progenitors defined by time of development, sympathoadrenal lineage markers and Mash-1-dependence. Development 122:309-320. Medline

Briscoe J, Pierani A, Jessell TM, Ericson J (2000) A homeodomain protein code specifies progenitor cell identity and neuronal fate in the ventral neural tube. Cell 101:435-445. CrossRef Medline

Castro DS, Martynoga B, Parras C, Ramesh V, Pacary E, Johnston C, Drechsel D, Lebel-Potter M, Garcia LG, Hunt C, Dolle D, Bithell A, Ettwiller L, Buckley N, Guillemot F (2011) A novel function of the proneural factor Ascl1 in progenitor proliferation identified by genome-wide characterization of its targets. Genes Dev 25:930-945. CrossRef Medline

Chen X, Ye R, Gargus JJ, Blakely RD, Dobrenis K, Sze JY (2015) Disruption of transient serotonin accumulation by non-serotonin-producing neurons impairs cortical map development. Cell Rep 10:346-358. CrossRef Medline

Danielian PS, Muccino D, Rowitch DH, Michael SK, McMahon AP (1998) Modification of gene activity in mouse embryos in utero by a tamoxifeninducible form of Cre recombinase. Curr Biol 8:1323-1326. CrossRef Medline

de Pontual L, Népote V, Attié-Bitach T, Al Halabiah H, Trang H, Elghouzzi V, Levacher B, Benihoud K, Augé J, Faure C, Laudier B, Vekemans M, Munnich A, Perricaudet M, Guillemot F, Gaultier C, Lyonnet S, Simonneau M, Amiel J (2003) Noradrenergic neuronal development is impaired by mutation of the proneural HASH-1 gene in congenital central hypoventilation syndrome (Ondine's curse). Hum Mol Genet 12:3173-3180. CrossRef Medline

Dubreuil V, Hirsch MR, Jouve C, Brunet JF, Goridis C (2002) The role of Phox $2 \mathrm{~b}$ in synchronizing pan-neuronal and type-specific aspects of neurogenesis. Development 129:5241-5253. Medline

Elworthy S, Pinto JP, Pettifer A, Cancela ML, Kelsh RN (2005) Phox2b function in the enteric nervous system is conserved in zebrafish and is sox10dependent. Mech Dev 122:659-669. CrossRef Medline

Fasano A, Visanji NP, Liu LW, Lang AE, Pfeiffer RF (2015) Gastrointestinal dysfunction in Parkinson's disease. Lancet Neurol 14:625-639. CrossRef Medline

Fode C, Ma Q, Casarosa S, Ang SL, Anderson DJ, Guillemot F (2000) A role for neural determination genes in specifying the dorsoventral identity of telencephalic neurons. Genes Dev 14:67-80. CrossRef Medline

Furness JB (2006) The enteric nervous system. Hoboken, NJ: Blackwell.

Furness JB (2012) The enteric nervous system and neurogastroenterology. Nat Rev Gastroenterol Hepatol 9:286-294. CrossRef Medline

Guillemot F, Lo LC, Johnson JE, Auerbach A, Anderson DJ, Joyner AL
(1993) Mammalian achaete-scute homolog 1 is required for the early development of olfactory and autonomic neurons. Cell 75:463-476. CrossRef Medline

Heanue TA, Pachnis V (2006) Expression profiling the developing mammalian enteric nervous system identifies marker and candidate Hirschsprung disease genes. Proc Natl Acad Sci U S A 103:6919-6924. CrossRef Medline

Heanue TA, Pachnis V (2011) Prospective identification and isolation of enteric nervous system progenitors using Sox2. Stem Cells 29:128-140. CrossRef Medline

Hegarty SV, Sullivan AM, O'Keeffe GW (2013) Midbrain dopaminergic neurons: a review of the molecular circuitry that regulates their development. Dev Biol 379:123-138. CrossRef Medline

Hirsch MR, Tiveron MC, Guillemot F, Brunet JF, Goridis C (1998) Control of noradrenergic differentiation and Phox2a expression by MASH1 in the central and peripheral nervous system. Development 125:599-608. Medline

Imayoshi I, Isomura A, Harima Y, Kawaguchi K, Kori H, Miyachi H, Fujiwara T, Ishidate F, Kageyama R (2013) Oscillatory control of factors determining multipotency and fate in mouse neural progenitors. Science 342 : 1203-1208. CrossRef Medline

Kim EJ, Ables JL, Dickel LK, Eisch AJ, Johnson JE (2011) Ascl1 (Mash1) defines cells with long-term neurogenic potential in subgranular and subventricular zones in adult mouse brain. PLoS One 6:e18472. CrossRef Medline

Kiyasova V, Gaspar P (2011) Development of raphe serotonin neurons from specification to guidance. Eur J Neurosci 34:1553-1562. CrossRef Medline

Lallemend F, Ernfors P (2012) Molecular interactions underlying the specification of sensory neurons. Trends Neurosci 35:373-381. CrossRef Medline

Laranjeira C, Sandgren K, Kessaris N, Richardson W, Potocnik A, Vanden Berghe P, Pachnis V (2011) Glial cells in the mouse enteric nervous system can undergo neurogenesis in response to injury. J Clin Invest 121:3412-3424. CrossRef Medline

Liu Y, Miao Q, Yuan J, Han S, Zhang P, Li S, Rao Z, Zhao W, Ye Q, Geng J, Zhang X, Cheng L (2015) Ascll converts dorsal midbrain astrocytes into functional neurons in vivo. J Neurosci 35:9336-9355. CrossRef Medline

Lo L, Anderson DJ (1995) Postmigratory neural crest cells expressing c-RET display restricted developmental and proliferative capacities. Neuron 15: 527-539. CrossRef Medline

Lo LC, Johnson JE, Wuenschell CW, Saito T, Anderson DJ (1991) Mammalian achaete-scute homolog 1 is transiently expressed by spatially restricted subsets of early neuroepithelial and neural crest cells. Genes Dev 5:1524-1537. CrossRef Medline

Lo L, Tiveron MC, Anderson DJ (1998) MASH1 activates expression of the paired homeodomain transcription factor Phox2a, and couples panneuronal and subtype-specific components of autonomic neuronal identity. Development 125:609-620. Medline

Ma Q, Kintner C, Anderson DJ (1996) Identification of neurogenin, a vertebrate neuronal determination gene. Cell 87:43-52. CrossRef Medline

Mongardi Fantaguzzi C, Thacker M, Chiocchetti R, Furness JB (2009) Identification of neurin types in the submucosal ganglia of the mouse ileum. Cell Tissue Res 336:179-189. CrossRef Medline

Narboux-Nême N, Pavone LM, Avallone L, Zhuang X, Gaspar P (2008) Serotonin transporter transgenic (SERTcre) mouse line reveals developmental targets of serotonin specific reuptake inhibitors (SSRIs). Neuropharmacology 55:994-1005. CrossRef Medline

Obermayr F, Hotta R, Enomoto H, Young HM (2013a) Development and developmental disorders of the enteric nervous system. Nat Rev Gastroenterol Hepatol 10:43-57. CrossRef Medline

Obermayr F, Stamp LA, Anderson CR, Young HM (2013b) Genetic fatemapping of tyrosine hydroxylase expressing cells in the enteric nervous system. Neurogastroenterol Motil 25:283-291. CrossRef

Pachnis V, Mankoo B, Costantini F (1993) Expression of the c-ret protooncogene during mouse embryogenesis. Development 119:1005-1017. Medline

Parras CM, Schuurmans C, Scardigli R, Kim J, Anderson DJ, Guillemot F (2002) Divergent functions of the proneural genes Mash1 and Ngn2 in the specification of neuronal subtype identity. Genes Dev 16:324-338. CrossRef Medline

Pattyn A, Simplicio N, van Doorninck JH, Goridis C, Guillemot F, Brunet JF 
(2004) Ascl1/Mash1 is required for the development of central serotonergic neurons. Nat Neurosci 7:589-595. CrossRef Medline

Pattyn A, Guillemot F, Brunet JF (2006) Delays in neuronal differentiation in Mash1/Ascl1 mutants. Dev Biol 295:67-75. CrossRef Medline

Pham TD, Gershon MD, Rothman TP (1991) Time of origin of neurons in the murine enteric nervous system: sequence in relation to phenotype. J Comp Neurol 314:789-798. CrossRef Medline

Qu ZD, Thacker M, Castelucci P, Bagyánszki M, Epstein ML, Furness JB (2008) Immunohistochemical analysis of neuron types in the mouse small intestine. Cell Tissue Res 334:147-161. CrossRef Medline

Sang Q, Young HM (1996) Chemical coding of neurons in the myenteric plexus and external muscle of the small and large intestine of the mouse. Cell Tissue Res 284:39-53. CrossRef Medline

Sang Q, Williamson S, Young HM (1997) Projections of chemically identified myenteric neurons of the small and large intestine of the mouse. J Anat 190:209-222. CrossRef Medline

Sang Q, Ciampoli D, Greferath U, Sommer L, Young HM (1999) Innervation of the esophagus in mice that lack MASH1. J Comp Neurol 408:1-10. CrossRef Medline

Sasselli V, Pachnis V, Burns AJ (2012) The enteric nervous system. Dev Biol 366:64-73. CrossRef Medline

Seo S, Lim JW, Yellajoshyula D, Chang LW, Kroll KL (2007) Neurogenin and NeuroD direct transcriptional targets and their regulatory enhancers. EMBO J 26:5093-5108. CrossRef Medline
Sommer L, Ma Q, Anderson DJ (1996) neurogenins, a novel family of atonal-related bHLH transcription factors, are putative mammalian neuronal determination genes that reveal progenitor cell heterogeneity in the developing CNS and PNS. Mol Cell Neurosci 8:221-241. CrossRef Medline

Srinivas S, Watanabe T, Lin CS, William CM, Tanabe Y, Jessell TM, Costantini F (2001) Cre reporter strains produced by targeted insertion of EYFP and ECFP into the ROSA26 locus. BMC Dev Biol 1:4. CrossRef Medline

Sugimori M, Nagao M, Parras CM, Nakatani H, Lebel M, Guillemot F, Nakafuku M (2008) Ascl1 is required for oligodendrocyte development in the spinal cord. Development 135:1271-1281. CrossRef Medline

van Dam S, Craig T, de Magalhães JP (2015) GeneFriends: a human RNAseq-based gene and transcript co-expression database. Nucleic Acids Res 43:D1124-D1132. CrossRef Medline

Vue TY, Kim EJ, Parras CM, Guillemot F, Johnson JE (2014) Ascll controls the number and distribution of astrocytes and oligodendrocytes in the gray matter and white matter of the spinal cord. Development 141:37213731. CrossRef Medline

Wakabayashi K, Mori F, Tanji K, Orimo S, Takahashi H (2010) Involvement of the peripheral nervous system in synucleinopathies, tauopathies and other neurodegenerative proteinopathies of the brain. Acta Neuropathol 120:1-12. CrossRef Medline 